DOI 10. 18307/2016. 0611

(c) 2016 by Journal of Lake Sciences

\title{
结合卫星遥感技术的太湖蓝藻水华形成温度特征分析
}

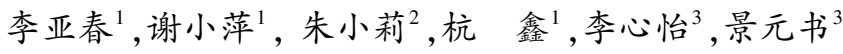 \\ ( 1 : 江苏省气象局, 南京 210008) \\ (2: 常州市气象局, 常州 213022) \\ (3: 南京信息工程大学, 南京 210044)
}

\begin{abstract}
摘 要: 气温对太湖蓝藻的复苏生长和水华形成、大面积暴发及衰退具有重要作用. 利用太湖湖面及周边地区 20032013 年气象与卫星观测数据分析, 结果发现太湖蓝藻水华形成的温度范围宽泛, 在蓝藻复苏后, 在日平均气温 $0 \sim 35.0^{\circ} \mathrm{C}$ 区间都能观测到蓝藻水华现象, 其中日平均气温 $15.1 \sim 35.0^{\circ} \mathrm{C}$ 区间为太湖蓝藻水华频发区间, 累计频次和面积占比分别 为 $85 \%$ 和 $90 \%$; 大面积蓝藻水华集中暴发的气温区间为 $20.1 \sim 35.0^{\circ} \mathrm{C}$, 累计频次和面积占比分别为 $72 \%$ 和 $73 \%$; 蓝藻水华 出现的概率随平均气温的升高而增大, 二者呈二次正相关关系, 而平均面积则随气温在均值附近波动, 日平均气温达 $33^{\circ} \mathrm{C}$ 后平均面积迅速减小. 表明气温并非复苏后太湖蓝藻水华出现与否的主要限制因子, 适度高温有利于蓝藻水华形成, 但在日平均气温 $33^{\circ} \mathrm{C}$ 以上时蓝藻水华会受到抑制. 在此基础上将蓝藻水华分成 4 个阶段: 休眠期、复苏期、增长期和衰退 期, 确定了基于气温的阶段量化指标, 对应起始和终止的界限温度分别为: $\left(0^{\circ} \mathrm{C}, 5^{\circ} \mathrm{C}\right) 、\left(5^{\circ} \mathrm{C}, 15^{\circ} \mathrm{C}\right) 、\left(15^{\circ} \mathrm{C}, 30^{\circ} \mathrm{C}\right)$ 和 $\left(30^{\circ} \mathrm{C}, 0^{\circ} \mathrm{C}\right)$, 据此可以计算出每年蓝藻水华的各生育阶段对应的时间节点,为防控提供依据.
\end{abstract}

关键词: 蓝藻水华;气温;卫星遥感;界限温度;太湖

\section{Applying remote sensing techniques in analysis of temperature features causing cya- nobacteria bloom in Lake Taihu}

\author{
LI Yachun ${ }^{1}$, XIE Xiaoping ${ }^{1}$, ZHU Xiaoli ${ }^{2}$, HANG Xin $^{1}$, LI Xinyi ${ }^{3} \&$ JING Yuanshu ${ }^{3}$ \\ (1: Meteorological Bureau of Jiangsu Province, Nanjing 210008, P.R.China) \\ (2: Changzhou Meteorological Bureau, Changzhou 213022 , P.R.China) \\ (3: Nanjing University of Information Science and Technology, Nanjing 210044, P.R. China)
}

\begin{abstract}
Air temperature plays an important role in the recruitmen, growth, and formation of cyanobacteria bloom, as well as, the large area outbreak and decline of water bloom in Lake Taihu. In order to find out the relationships between the formation of cyanobacteria bloom in Lake Taihu and surface temperature, meteorological data and satellite observations of the lake and surrounding areas from 2003 to 2013 were used to perform quantitative analysis in this paper. It is found that there is a wide range of daily average temperature $\left(0-35.0^{\circ} \mathrm{C}\right)$ suitable for cyanobacteria bloom appearing. Specifically, when daily average temperature falls between 15.1 and $35.0^{\circ} \mathrm{C}$, the frequency of cyanobacteria bloom occurrences increases, leading to the accumulate frequency and accumulate area of cyanobacteria bloom accounted for $85 \%$ and $90 \%$, respectively. The large area of cyanobacteria bloom mainly occurs in the daily average temperature range from 20.1 to $35.0^{\circ} \mathrm{C}$, with the accumulate frequency and accumulate area accounted for $72 \%$ and $73 \%$, respectively. Meanwhile, the probability of cyanobacteria bloom appearance increases as average temperature rising, showing a quadratic positive correlation. Moreover, single average area of cyanobacteria bloom fluctuates near the mean value of temperature, which decreases rapidly when daily average temperature reaches $33^{\circ} \mathrm{C}$.It shows that temperature is not the limiting factor for appearance of cyanobacteria bloom after it is resuscitated. Moderate high temperature benefits formation of cyanobacteria bloom, and becomes inhibiting factor when it reaches above $33^{\circ} \mathrm{C}$. On the basis of analysis, the relationship to temperature, quantitative indicators of four stages of cyanobacteria bloom are identified. These four stages include dormant, recruitmen, growth and decline pe-
\end{abstract}

* 江苏省基础研究计划太湖专项( BK2007745)、江苏省科技支撑计划项目 (BE2011840) 和江苏省气象局重点项目 (KZ201403) 联合资助. 2015-10-22 收稿;2016-01-20 收修改稿. 李亚春( 1966 ), 男,硕士,研究员级高级工程 师; E-mail: jsqxlyc@163.com. 
riods, and their initial and final critical temperature are $\left(0^{\circ} \mathrm{C}, 5^{\circ} \mathrm{C}\right),\left(5^{\circ} \mathrm{C}, 15^{\circ} \mathrm{C}\right),\left(15^{\circ} \mathrm{C}, 30^{\circ} \mathrm{C}\right)$ and $\left(30^{\circ} \mathrm{C}, 0^{\circ} \mathrm{C}\right)$, respectively. Relating to critical temperature, the corresponding date could be pinpointed for the four stages of cyanobacteria bloom. This study provides a basis for the prevention and control of algae bloom.

Keywords: Cyanobacteria bloom; surface temperature; remote sensing; critical temperature; Lake Taihu

近几十年来蓝藻水华事件增多趋势已成为全球广泛关注的问题 ${ }^{[1-2]}$, 其中水体富营养化和气候变暖被 认为是 2 个重要的原因,但其对蓝藻水华的影响机制很复杂 ${ }^{[3-4]}$. Rigosi 等 ${ }^{[5]}$ 根据对 1000 个湖泊的最新研究 表明,富营养化和气候变暖及其相互作用对蓝藻水华的贡献主要依赖于水体的营养程度和藻类种群, 当水 体变得更富营养时,蓝藻水华对其相互作用也更敏感,但营养盐浓度是预测蓝藻水华的更重要因子.一般认 为, 充足的营养物质和适宜的气象水文条件是蓝藻水华发生的必要条件, 而在湖泊水质富营养化程度长期 得不到控制的情况下, 气象条件可能成为其主要限制因子 ${ }^{[6-8]}$, Zhang 等 ${ }^{[9]}$ 的研究表明, 气候变暖是近 20 年 来太湖蓝藻水华次数增多和强度增强的主要原因. 现有的研究已证实, 气温与风 ${ }^{[10-12]}$ 、光照和降水 ${ }^{[13]}$ 等气象 因子都会对蓝藻生长和水华形成产生重要影响,而不同的气象因子及其在蓝藻生长和水华形成的不同阶段 所起的作用也可能明显不同. 有些学者认为温度起着重要作用. 如 Peperzak ${ }^{[14]}$ 就认为蓝藻水华的发生主要是 由于水温升高而引发; 2007 年太湖蓝藻水华的提前暴发, 当年冬、春季异常偏高的气温也被认为是其关键诱 因 ${ }^{[15]}$. 另外有些研究证实温度是影响蓝藻复苏的关键因子. 如吴晓东等 ${ }^{[16]}$ 认为气温升高使得太湖的水温升 高, 从而提高蓝藻的原位生长速率; 陶益等 ${ }^{[17]}$ 在室内复苏模拟实验中确定了太湖藻类复苏的温度阈值: 在水 体温度达到 $14^{\circ} \mathrm{C}$ 时蓝藻开始少量进人水柱中; 谭啸等 ${ }^{[18]}$ 发现蓝澡在 $12.5^{\circ} \mathrm{C}$ 时开始复苏, 且复苏后的蓝藻具 有较高的比生长速率,有利于其确立优势地位而形成水华;Zhang 等 ${ }^{[19]}$ 也证实春季温度的波动很可能会促 进水华蓝藻种群优势地位的更早确立. Cao 等 ${ }^{[20]}$ 发现在实验室里蓝藻复苏的气温介于 $5 \sim 9^{\circ} \mathrm{C}$ 之间, 进人水 体的气温也为 $14^{\circ} \mathrm{C}$, 而在太湖实地观测中, 蓝藻复苏和进人水体的气温都是 $9^{\circ} \mathrm{C}$, 可见由于实验室环境与野 外明显不同, 因此观测得到的蓝藻复苏温度也存在明显差异. 在蓝藻复苏以后, 虽然一般认为温度对蓝藻生 长的作用可能并没有那么重要, 但水华的暴发却与高温密切相关, 黄炜等 ${ }^{[21]}$ 认为太湖蓝澡水华暴发概率与 气温呈正相关关系, Chen 等 ${ }^{[22]}$ 认为太湖微囊藻的最适生长温度为 $30 \sim 35^{\circ} \mathrm{C}$, 水库中的围隔实验也证实当水 温为 $26^{\circ} \mathrm{C}$ 时, 最适宜于微囊藻的聚集、上浮而形成水华 ${ }^{[23]}$. 上述研究都表明, 温度对蓝藻复苏、生长和水华形 成及暴发都起着重要甚至关键作用,但这些研究大多基于实验室或短时间、局部的实地观测数据,对于太湖 这样一个大型浅水湖泊 (面积达 $2338 \mathrm{~km}^{2}$ ), 蓝藻水华面积也常达数百平方公里, 短时间、局部的实地观测或 者基于实验室的研究显然难以客观反映蓝藻水华与环境温度之间的关系.

因此, 本文利用太湖湖面及周边地区较长时间、连续高频的气象观测数据及同步卫星监测数据, 深人分 析太湖蓝藻水华形成的温度特征, 为进一步研究蓝藻水华形成机理提供理论依据, 为太湖蓝藻水华的预测、 预警和防控提供技术支持.

\section{1 资料与方法}

\section{1 资料}

气象资料来源于江苏省气象局, 主要选用太湖周边区域的湖州、宜兴、无锡、苏州、吴中和东山 6 个基本 站 2003-2013 年的逐日气温观测资料、湖面及周边 23 个区域自动站 2009-2013 年的逐时气温观测资料 (图 1).

卫星数据来源于国家卫星气象中心和江苏省气象局, 选用 2003-2013 年的 Aqua/Terra 卫星 (EOS/MODIS) 和 FY-3 卫星 (MERSI) 观测的影像数据,空间分辨率为 $250 \mathrm{~m}$.

\section{2 太湖蓝藻的遥感解译方法}

在蓝藻水华的众多遥感解译方法中 ${ }^{[24-26]}$, 归一化植被指数法 $(N D V I)$ 是目前常用的一种方法:

$$
N D V I=\left(\rho_{\text {nir }}-\rho_{\text {red }}\right) /\left(\rho_{\text {nir }}+\rho_{\text {red }}\right)
$$

式中, $\rho_{\text {nir }}$ 为近红外波段反射率, 分别对应于 MODIS 第 2 通道和 MERSI 第 4 通道的反射率值, $\rho_{\text {red }}$ 为红光波段 反射率, 分别对应于 MODIS 第 1 通道和 MERSI 第 3 通道的反射率值. 蓝藻水华的 NDVI 阈值需根据观测时 


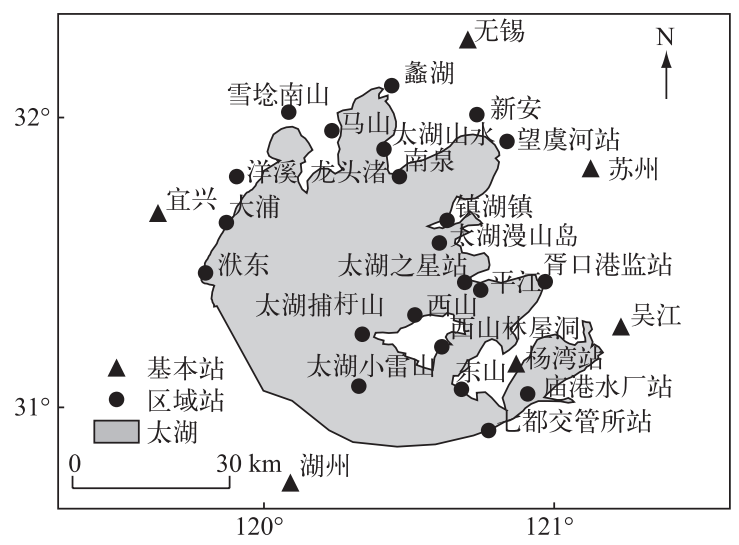

图 1 气象数据采样点位置

Fig. 1 Location of the sampling meteorological sites

刻的大气状况、卫星天顶角并结合目视情况确定,范围在-0.15 0.10. 本文用 $N D V I$ 法解译得到 2003-2013 年累计 805 幅太湖蓝澡水华面积 $\geqslant 1 \mathrm{~km}^{2}$ 的卫星遥感影像, 分别计算得到蓝藻水华的频次、面积、时间及位置 信息等.

大面积的蓝藻水华暴发对太湖水质及周边城市饮用水的影响尤其明显, 为此, 本文将专门分析大面积 蓝澡水华形成与气温的关系. 定义单次蓝藻水华面积超过太湖水面面积的 $20 \%$ 或 $468 \mathrm{~km}^{2}$ 以上的为大面积 蓝藻水华,得到大面积蓝藻水华卫星遥感影像样本 62 个,除 2003 年以外其它年份均有发生.

\section{3 蓝藻水华出现概率的计算方法}

为考察各气温区间对蓝藻水华形成的影响, 考虑到各气温区间内适宜卫星遥感的“晴空” 日数可能存在 明显差异, 因此仅使用蓝藻水华出现的频次及其占比并不能客观反映各气温区间的影响. 为此, 计算蓝藻水 华出现的概率 $\left(P_{i}\right)$ :

$$
P_{i}=T_{i} / T_{\text {total }} \times 100 \%
$$

式中, $P_{i}$ 为第 $i$ 气温区间内蓝藻水华出现概率, $T_{i}$ 为第 $i$ 气温区间内蓝藻水华出现日数, $T_{\text {total }}$ 为第 $i$ 气温区间 内除去云量 $\geqslant 8$ 的总日数.

为考察蓝藻水华的发生与气温之间的关系, 采用非线性统计回归方法拟合蓝藻水华概率与气温之间的 关系.

\section{4 界限温度的计算方法}

农学和气象学上把具有普遍意义的、标志某些重要物候现象或农事活动之开始、终止或转折点的日平 均温度称作界限温度. 为了解太湖蓝藻水华生育进程与气温的关系, 本文引用界限温度的概念, 并用五日滑 动平均法来计算稳定通过界限温度的时间.初日的算法: 从春季达到该界限温度的第 $1 \mathrm{~d}$ 开始, 计算第 $1 \sim 5 \mathrm{~d}$ 的平均值, 将此平均值作为第 $1 \mathrm{~d}$ 的五日滑动平均值; 再求第 $2 \sim 6 、 3 \sim 7 \mathrm{~d} \cdots \cdots$. 以此类推, 选取五日滑动平均 值大于该界限温度并且之后均大于该界限温度的连续 $5 \mathrm{~d}$, 把这连续 $5 \mathrm{~d}$ 中的第 $1 \mathrm{~d}$ 作为界限温度的初日; 终 日的算法: 从秋季日平均气温第一次出现低于某界限温度之日起,向前推 $4 \mathrm{~d}$,按日序依次计算出每连续 $5 \mathrm{~d}$ 的 平均气温, 并从中选出第一个出现<该界限温度且在其后不再出现 $5 \mathrm{~d}$ 平均气温高于该界限温度的前一个连 续 $5 \mathrm{~d}$, 此 $5 \mathrm{~d}$ 中最后一个日平均气温？该界限温度的日期即终日.

\section{2 结果}

\section{1 蓝藻水华形成的温度分布}

2003-2013 年卫星监测到太湖蓝藻水华时对应的当日日平均气温范围为 $0 \sim 35.0^{\circ} \mathrm{C}$ ( 图 2), 而卫星监测 时刻所在的 $1 \mathrm{~h}$ 平均气温最高为 $38.7^{\circ} \mathrm{C}$, 出现于 2013 年 8 月 9 日 $13: 00$, 蓝藻水华面积为 $112.6 \mathrm{~km}^{2}$, 最低气 
温为 $2.8^{\circ} \mathrm{C}$, 出现于 2005 年 12 月 18 日 $10: 00$, 蓝藻水华面积为 $450.7 \mathrm{~km}^{2}$. 表明蓝藻水华形成的温度范围十 分宽泛, 在 $0^{\circ} \mathrm{C} \leqslant$ 日平均气温 $\leqslant 35.0^{\circ} \mathrm{C}$ 或 $2.8^{\circ} \mathrm{C} \leqslant$ 小时平均气温 $\leqslant 38.7^{\circ} \mathrm{C}$ 的情况下, 太湖都有可能出现蓝藻水 华的聚集现象.

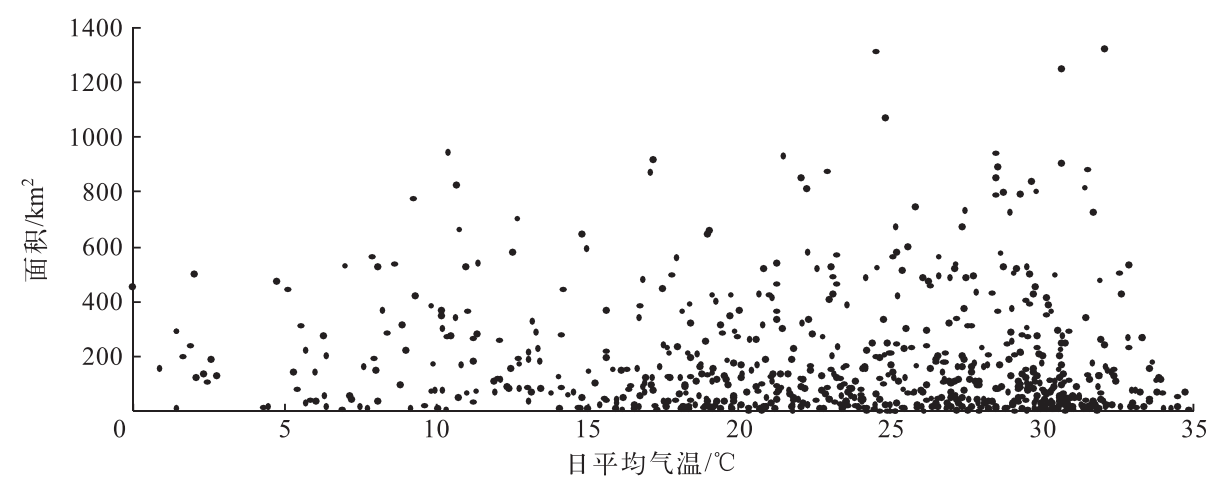

图 2 2003-2013 年太湖蓝藻水华面积及对应气温分布

Fig.2 Cyanobacteria bloom area and corresponding daily mean temperature in Lake Taihu during 2003-2013

将日平均气温按每隔 $5^{\circ} \mathrm{C}$ 分成 7 个温度区间, 统计太湖蓝藻水华在各气温区间的频次与面积及各自所 占比例 (表 1), 结果可见, 蓝藻水华频次随气温升高而增大, $0 \sim 5^{\circ} \mathrm{C}$ 区间频次最少, 占比仅 $2 \%, 25.1 \sim 30.0^{\circ} \mathrm{C}$ 区间达峰值, 占比 $28 \%, 15.1 \sim 35.0^{\circ} \mathrm{C}$ 气温区间累计频次占比达 $85 \%$; 蓝藻水华累计面积总体上也随气温升 高而增大, 但最小值出现在 $10.1 \sim 15.0^{\circ} \mathrm{C}$ 气温区间, 占比仅 $1 \%$, 而最大值仍出现在 $25.1 \sim 30.0^{\circ} \mathrm{C}$ 区间, 占比 达 $31 \%, 15.1 \sim 35.0^{\circ} \mathrm{C}$ 气温区间累计面积占比达 $90 \%$.

\section{2 大面积蓝藻水华形成的温度分布}

各气温区间大面积蓝藻水华的频次与面积及占比情况可见, 大面积蓝藻水华的出现也几乎覆盖了 $0^{\circ} \mathrm{C}$ 以 上的气温区间,其中在 $20^{\circ} \mathrm{C}$ 前各气温区间的频次和面积占比相对平稳增加, 但 $20^{\circ} \mathrm{C}$ 后明显增大, 在 $25.1 \sim 30^{\circ} \mathrm{C}$ 间均达最大,频次和面积占比分别为 $40 \%$ 和 $38 \%$, 而日平均气温在 $20.1 \sim 35^{\circ} \mathrm{C}$ 区间累计频次和面积占比分别为 $72 \%$ 和 $73 \%$. 表明大面积蓝藻水华主要出现在日平均气温 $\geqslant 20^{\circ} \mathrm{C}$ 的情况下, 其中 $25.1 \sim 30^{\circ} \mathrm{C}$ 为高发区间 (表 2 ).

表 $12003-2013$ 年各气温区间太湖蓝藻水华面积及频次占比

Tab.1 The accumulate area and accumulate frequency proportion of cyanobacteria

bloom in each mean temperature range during 2003-2013

\begin{tabular}{lccccccc}
\hline \multirow{2}{*}{ 蓝藻水华 } & \multicolumn{7}{c}{ 气温区间 $/{ }^{\circ} \mathrm{C}$} \\
\cline { 2 - 8 } & $0 \sim 5.0$ & $5.1 \sim 10.0$ & $10.1 \sim 15.0$ & $15.1 \sim 20.0$ & $20.1 \sim 25.0$ & $25.1 \sim 30.0$ & $30.1 \sim 35.0$ \\
\hline 频次占比 $/ \%$ & 2 & 5 & 8 & 16 & 22 & 28 & 19 \\
面积占比 $/ \%$ & 3 & 6 & 1 & 14 & 21 & 31 & 15 \\
\hline
\end{tabular}

表 $22003-2013$ 年各气温区间太湖大面积蓝藻水华面积及频次占比

Tab.2 The accumulate area and accumulate frequency proportion of wide area cyanobacteria bloom in Lake Taihu in each mean temperature range during 2003-2013

\begin{tabular}{lccccccc}
\hline \multirow{2}{*}{ 大面积蓝藻水华 } & \multicolumn{7}{c}{ 气温区间 $/{ }^{\circ} \mathrm{C}$} \\
\cline { 2 - 8 } & $0 \sim 5.0$ & $5.1 \sim 10.0$ & $10.1 \sim 15.0$ & $15.1 \sim 20.0$ & $20.1 \sim 25.0$ & $25.1 \sim 30.0$ & $30.1 \sim 35.0$ \\
\hline 频次占比 $/ \%$ & 3 & 6 & 11 & 9 & 19 & 40 & 13 \\
面积占比 $/ \%$ & 2 & 6 & 11 & 9 & 20 & 38 & 15 \\
\hline
\end{tabular}




\section{3 蓝藻水华概率及平均面积对气温的响应}

$1{ }^{\circ} \mathrm{C}$ 气温区间蓝藻水华概率与平均面积分布图 (图 3) 可见, 蓝藻水华概率随气温升高而波动增大, 概率 与气温呈如下关系 :

$$
p=0.063 t^{2}-0.741 t+7.773
$$

式中, $p$ 表示蓝藻水华概率, $t$ 表示气温, $R^{2}=0.89\left(p_{0.01}=0.41282\right)$, 通过 0.01 显著性检验.

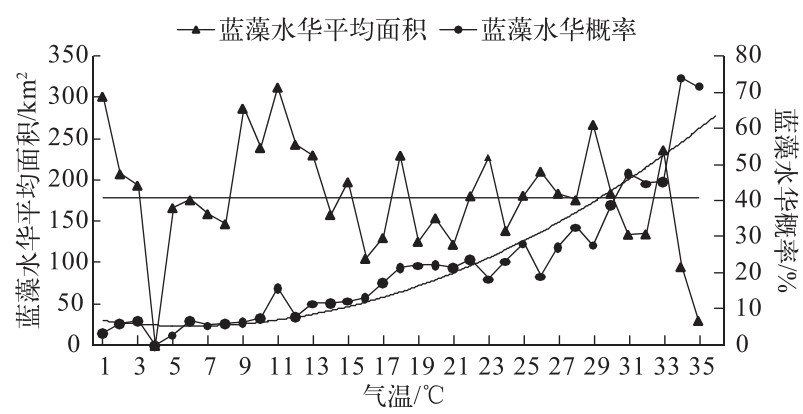

图 3 蓝藻水华概率和平均面积与气温 $\left(1^{\circ} \mathrm{C}\right.$ 区间 $)$ 的分布

Fig. 3 The distribution curve between probability, mean area of cyanobacteria bloom and mean temperature in Lake Taihu

蓝藻水华平均面积随气温的升高变化不大, 总体上沿均值上下波动, 但其中有 2 个明显的低值点需要 引起注意. 第一个低值点位于 $4^{\circ} \mathrm{C}$ 而不是 $0^{\circ} \mathrm{C}$ 附近, 这表明虽然进人冬季后气温显著下降, 但由于人冬后蓝藻 的沉降和休眠有一个滞后的时间, 前期累积的生物量在一般甚至不适宜的气象水文条件下仍能形成蓝藻水 华, 证明了蓝藻水华在人冬后比春季具有更强的耐受低温的能力, 蓝藻水华复苏所需的气温明显高于衰亡 所需要的气温, 事实上, 在大部分年份的 12 月或 1 月卫星都观测到了蓝藻水华现象, 最低日平均气温为 $0^{\circ} \mathrm{C}$. 另一个低点在 $35^{\circ} \mathrm{C}$ 附近, 之前在 $15 \sim 33^{\circ} \mathrm{C}$ 区间平均面积围绕均值波动, 至 $33^{\circ} \mathrm{C}$ 达相对高点后急速向下, 表明 在日平均气温达 $33^{\circ} \mathrm{C}$ 左右后蓝藻水华平均面积迅速减小.

\section{3 讨论}

在 1980s 之前, 太湖流域气象条件的年代际尺度变化趋势不利于蓝藻生长和水华形成, 而 $1980 \mathrm{~s}$ 以后, 尤其是 $1990 \mathrm{~s}$ 以后, 气候变化有利于太湖蓝藻生长和水华形成 ${ }^{[27-28]}$. 在此背景下, 在中小型湖泊较多的我国 长江中下游地区, 多数湖泊正处于富营养化或已经重度营养化 ${ }^{[29]}$, 因而近年来蓝藻水华频率增加、程度加重 的趋势较明显, 如巢湖、阳澄湖、鄱阳湖等, 甚至连一些水库都出现了不同程度的蓝藻水华 ${ }^{[30-31]}$.气候变化和 水质富营养化及其相互作用对蓝藻水华的影响较为复杂, 但现有研究结果表明这两种过程可能增强蓝藻水 华的频率和程度 ${ }^{[3-5]}$, 因此需要进一步深人研究气温对蓝藻水华形成机制的影响.

\section{1 蓝藻水华的四阶段划分及气温指标}

在长期的生存繁衍进程中, 蓝藻逐渐形成了与自然气候交替变化相似的周期变化特征. 孔繁翔等 ${ }^{[6]}$ 提出 蓝藻生长与水华形成的四阶段理论假说, 即休眠、复苏、生物量增加和上浮和积聚.作者在此基础上依据蓝藻 水华与气温的关系,试图获取蓝藻水华四阶段的定量气温指标及对应日期.按时间序列将日平均气温分成间 隔为 $5^{\circ} \mathrm{C}$ 的 14 个温度区间, 统计太湖蓝藻水华在各气温区间的面积和频次所占比例, 结果表明太湖蓝藻水 华面积和频次占比曲线均呈单峰形状, 有 3 个相对明显的拐点, 分别是 4 月 15 日 (稳定通过该温度的日期, 下同) 的 $15^{\circ} \mathrm{C}, 7$ 月 24 日的 $30^{\circ} \mathrm{C}$ 和 11 月 4 日的 $15^{\circ} \mathrm{C}$ (图 4). 根据曲线主要拐点, 结合四阶段理论假说, 将蓝 藻生长与水华形成划分为 4 个阶段: 休眠期、复苏期、增长期和衰退期. 在休眠期 ( 日平均气温 $0 \sim 5^{\circ} \mathrm{C}$, 对应日 期为 2 月 23 日前), 蓝藻生命代谢过程可能基本停止, 卫星观测不到蓝藻水华; 在复苏期 (日平均气温 5 $15^{\circ} \mathrm{C}, 2$ 月 23 日至 4 月 15 日), 蓝藻生理、生化活性缓慢恢复, 群体形成, 在适宜的气象、水文环境条件下上 浮形成水华, 卫星开始观测到蓝藻水华形成, 但频次和面积占比均很小, 仅分别为 $0.27 \%$ 和 $0.02 \%$; 在增长期 
(日平均气温 $15 \sim 30^{\circ} \mathrm{C}, 4$ 月 15 日至 7 月 24 日), 随着气温的升高, 蓝藻光合作用强, 细胞增殖快, 生物量迅 速增长, 在适宜的环境条件影响下大量聚集形成水华, 卫星观测到蓝藻水华的频次和面积迅速增加, 分别在 $30 \sim 35^{\circ} \mathrm{C}$ 和 $35 \sim 30^{\circ} \mathrm{C}$ 区间达到峰值, 占比达 $19.27 \%$ 和 $21.63 \%$; 此后, 蓝藻水华可能进入衰退期 $\left(30 \sim 0^{\circ} \mathrm{C}, 7\right.$ 月 24 日以后), 随气温的逐渐下降, 蓝藻水华频次和面积占比也降低, 但在较长一段时间内气温处于蓝藻水 华的适宜温度范围, 因此频次和面积仍维持较高水平, 至 $15^{\circ} \mathrm{C}$ ( 11 月 4 日) 后迅速下降直至 0 , 将这一子阶段 称为蓝藻水华的下沉期.

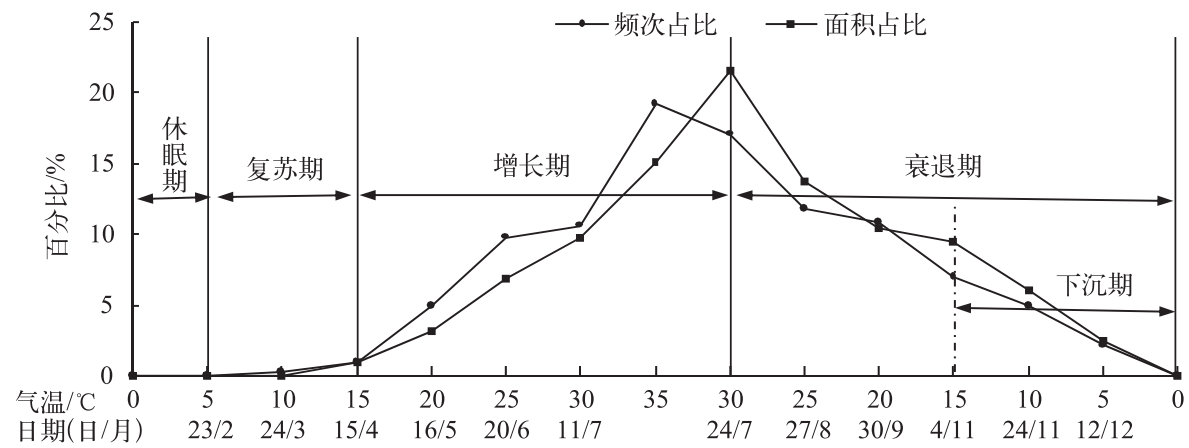

图 4 太湖蓝藻水华的主要阶段划分及对应的气温与日期

Fig.4 The main phase division of cyanobacteria bloom and corresponding critical temperature and date in Lake Taihu

确定各阶段温度指标可以掌握蓝藻水华的生育进程及时间节点, 有助于蓝藻水华的预测预警和科学防 控. 复苏期起始温度为日平均气温稳定通过 $5^{\circ} \mathrm{C}$, 而实际日平均气温应该明显高于 $5^{\circ} \mathrm{C}$, 同时考虑到此时太湖 水体温度要高于气温且存在垂直水温差, 因此这一界限温度指标与 $\mathrm{Cao}$ 等 ${ }^{[20]}$ 的 $5 \sim 9^{\circ} \mathrm{C}$ 气温及 Reynolds ${ }^{[32]}$ 的 $7 \sim 8^{\circ} \mathrm{C}$ 水温基本吻合. 从卫星观测到的太湖蓝藻水华逐月频次和面积 (表 3) 可以看出, 卫星观测到蓝藻水华 的最早日期为 3 月 9 日, 在此前的 1 月中旬至 2 月下旬期间都没有蓝藻水华, 因此, 将未观测到蓝藻水华的 一段时期称为休眠期, 事实上, $1-2$ 月太湖湖区底泥表面藻蓝素浓度为年内最低 ${ }^{[33]}$. 对应秋季温度为 $15^{\circ} \mathrm{C}$ (对应日期为 11 月 4 日), 蓝藻水华开始进人下沉期, 这一指标与相关文献相似: Abbots 池塘中微囊藻的下 沉临界温度为 $8 \sim 12^{\circ} \mathrm{C}^{[34]}$, Rosherne 湖中微囊藻的下沉临界温度为 $9 \sim 11^{\circ} \mathrm{C}^{[35]}$, Harbeesport 水库中微囊藻的 临界温度 $<12.8^{\circ} \mathrm{C}^{[36]}$, 吴晓东等 ${ }^{[37]}$ 也证实 11 月时太湖蓝藻水华大量下沉进人底泥.

表 $32003-2013$ 年太湖蓝藻水华月累计频次和面积

Tab.3 The accumulate area and frequency of cyanobacteria bloom in each month in Lake Taihu during 2003-2013

\begin{tabular}{|c|c|c|c|c|c|c|c|c|c|c|c|c|}
\hline & 1 月 & 2 月 & 3 月 & 4 月 & 5 月 & 6 月 & 7 月 & 8 月 & 9 月 & 10 月 & 11 月 & 12 月 \\
\hline 累计面积 $/ \mathrm{km}^{2}$ & 17 & 0 & 8 & 213 & 824 & 446 & 1120 & 2317 & 2691 & 1834 & 1433 & 815 \\
\hline 累计频次 & 92 & 0 & 31 & 73 & 111 & 76 & 107 & 182 & 233 & 159 & 222 & 204 \\
\hline
\end{tabular}

\section{2 蓝藻水华的适宜气温范围}

气温对不同阶段蓝藻生长和水华形成会产生不同的影响.根据分析结果, 在复苏以后,蓝藻水华出现的 气温范围覆盖了日平均气温为 $0 \sim 35.0^{\circ} \mathrm{C}$ 区间, 表明气温并非复苏后蓝藻水华出现与否的主要限制因子. 但 气温对蓝藻的复苏生长起着关键作用. 相关的研究已证实蓝藻的生长复苏需要达到一定的水温条件 ${ }^{[19,21,37]}$. 较高的气温对蓝藻生长和水华形成具有促进作用. 太湖蓝藻水华出现的概率与气温呈二次正相关关系, 与 文献 $[21,31]$ 结论基本相符, 平均面积随气温在均线上下波动, 但日平均气温达 $33^{\circ} \mathrm{C}$ 后平均面积迅速减小, 说明在 $33^{\circ} \mathrm{C}$ 以上高温情况下, 蓝藻的增殖受到一定程度的抑制. 在 2013 年 7 月 1 日至 8 月 14 日, 太湖地区 出现创历史极值的持续高温晴热天气, 虽然期间观测到蓝藻水华频次为 2007 年以来同期最多, 但单次最大 面积和平均面积却为同期最小, 这一观测事实也证实了上述结果. 卫星观测到蓝藻水华主要出现在日平均气 
温为 $15.1 \sim 35.0^{\circ} \mathrm{C}$, 而在 $25.1 \sim 30.0^{\circ} \mathrm{C}$ 区间内频率最高, 累计面积也最大, 大面积蓝藻水华高发区间也为 $25.1 \sim$ $30.0^{\circ} \mathrm{C}$, 表明太湖蓝藻水华的最适宜气温区间为 $25.1 \sim 30.0^{\circ} \mathrm{C}$, 与 Hua 等 ${ }^{[23]}$ 的实验结果基本相符.

尽管对于长江中下游地区其它湖泊蓝藻水华的研究远不如太湖这么多, 但已有研究得到了类似的结果. 如关于蓝藻水华暴发的最适宜温度, 淀山湖为 $24.2 \sim 30.5^{\circ} \mathrm{C}^{[29]}$, 巢湖为 $22.0 \sim 30.0^{\circ} \mathrm{C}^{[39]}$, 阳澄湖为前 $5 \mathrm{~d}$ 平 均气温 $30^{\circ} \mathrm{C}^{[40]}$; 关于蓝藻水华的不同阶段说法, 吴晓东等 ${ }^{[37]}$ 认为巢湖也存在与太湖类似的下沉越冬和春季 复苏规律. 因此, 本文有关太湖蓝藻水华形成的温度特征的研究结果, 也可以为研究长江中下游地区其它湖 泊蓝藻水华的规律提供参考.

\section{4 结论}

1 )气温对太湖蓝藻的复苏生长和水华形成、衰退及大面积暴发具有重要作用. 在蓝藻复苏后, 在日平均 气温 $0 \sim 35.0^{\circ} \mathrm{C}$ 区间都能观测到蓝藻水华现象, 表明气温并非复苏后蓝藻水华出现与否的主要限制因子. 适度 高温有利于蓝藻水华形成, 太湖蓝藻水华主要出现在日平均气温为 $15.1 \sim 35.0^{\circ} \mathrm{C}$ 的区间, 日平均气温 $25.1 \sim$ $30.0^{\circ} \mathrm{C}$ 区间为蓝藻水华频发区, 也是大面积蓝藻水华集中暴发区.

2) 太湖蓝藻水华出现的概率随平均气温的升高而增大, 二者呈二次正相关关系, 而平均面积随气温在 均线上下波动, 日平均气温达 $33^{\circ} \mathrm{C}$ 后平均面积迅速减小, 表明日平均气温在 $33^{\circ} \mathrm{C}$ 以上时蓝藻水华受到抑制.

3 ) 太湖蓝藻水华可分为 4 个阶段: 休眠期、复苏期、增长期和衰退期, 对应的起始和终止界限温度分别 为 $\left(0^{\circ} \mathrm{C}, 5^{\circ} \mathrm{C}\right) 、\left(5^{\circ} \mathrm{C}, 15^{\circ} \mathrm{C}\right) 、\left(15^{\circ} \mathrm{C}, 30^{\circ} \mathrm{C}\right)$ 和 $\left(30^{\circ} \mathrm{C}, 0^{\circ} \mathrm{C}\right)$, 根据界限温度可以计算出每年蓝藻水华的各个生 育阶段对应的时间节点, 从而为防控提供依据.

\section{5 参考文献}

[ 1 ] Shu HT, Chen EY, Gin KY. Comparison of quantitative PCR and droplet digital PCR multiplex assays for two genera of bloom-forming cyanobacteria, Cylindrospermopsis and Microcystis. Applied and Environmental Microbiology, 2015, 81 (15) : 5203-5211.

[ 2 ] Bista D, Heckathorn SA, Bridgeman T et al. Interactive effects of temperature, nitrogen, and zooplankton on growth and protein and carbohydrate content of cyanobacteria from western Lake Erie. Journal of Water Resource and Protection, 2014, 6(12) : 1139-1153.

[ 3 ] O' Neila JM, Davisb TW, Burfordb MA et al. The rise of harmful cyanobacteria blooms: The potential roles of eutrophication and climate change. Harmful Algae, 2012, (14) : 313-334.

[ 4 ] Paerl HW, Otten TG. Harmful cyanobacterial blooms: Causes, consequences, and controls. Microbial Ecology, 2013, 65 (4) : 995-1010.

[ 5 ] Rigosi A, Carey CC, Ibelings BW et al. The interaction between climate warming and eutrophication to promote cyanobacteria is dependent on trophic state and varies among taxa. Limnology and Oceanography, 2014, 59(1) : 99-114.

[ 6 ] Kong Fanxiang, Gao Guang. Hypothesis on cyanobacteria bloom-forming mechanism in large shallow eutrophic lakes. Acta Ecologica Sinica, 2005, 25(3) : 589-595(in Chinese with English abstract). [孔繁翔, 高光. 大型浅水富营养化湖泊 中蓝藻水华形成机理的思考. 生态学报, 2005, 25(3): 589-595.]

[ 7 ] Kanoshina I, Lips U, Leppanen JM. The influence of weather conditions(temperature and wind) on cyanobacterial bloom development in the Gulf of Finland(Baltic Sea). Harmful Algae, 2003, (2) : 29-41.

[ 8 ] Cao HS, Kong FX, Luo LC et al. Effects of wind and wind-induced waves on vertical phytoplankton distribution and surface blooms of Microcystis aeruginosa in Lake Taihu. Journal of Freshwater Ecology, 2006, 21(2) : 231-238.

[ 9 ] Zhang M, Duan HT, Shi XL et al. Contributions of meteorology to the phenology of cyanobacterial blooms: implications for future climate change. Water Research, 2012, 46(2): 442-452.

[10] Wang Chenglin, Huang Juan, Qian Xin. Spatio tempoal characteristics of wind field under high temperature and gentle breeze in Taihu Basin. J Lake Sci, 2011, 23(1): 122-128(in Chinese with English abstract). DOI: 10.18307/2011. 0118. [王成林, 黄娟, 钱新. 高温微风条件下太湖流域风场时空特征分析. 湖泊科学, 2011, 23(1): 122-128.]

[11] Wu Tingfeng, Zhu Guangwei, Qin Boqiang et al. Prior wind field induced hydrodynamics and its influence on cyanobacterial bloom in northern bays of Lake Taihu, China. J Lake Sci, 2012, 24(3) : 409-415( in Chinese with English abstract). 
DOI: 10.18307/2012.0312. [ 吴挺峰, 朱广伟, 秦伯强等. 前期风场控制的太湖北部湖湾水动力及对蓝藻水华影响. 湖泊科学, 2012, 24(3): 409-415.]

[12] Qin Boqiang, Hu Weiping, Gao Guang et al. Dynamics of sediment resuspension and the conceptual schema of nutrient release in the large shallow Lake Taihu, China. Chinese Science Bulletin, 2003, 48(17) : 1822-1831( in Chinese with English abstract). [ 秦伯强, 胡维平, 高光等. 太湖沉积物悬浮的动力机制及内源释放的概念性模式. 科学通报, 2003, 48(17) : 1822-1831.]

[13] Wu Shengli, Liu Cheng, Sun Jun et al. Remote sensing and analysis on meteorological factors of blue algal bloom in Lake Taihu. Meteorological Monthly, 2009, 35(1): 18-23(in Chinese with English abstract). [武胜利, 刘诚, 孙军等. 卫星 遥感太湖蓝藻水华分布及其气象影响要素分析. 气象, 2009, 35(1): 18-23.]

[14] Peperzak L. Climate change and harmful algal blooms in the North Sea. ACTAO Ecilogica, 2003, (24) : 139-144.

[15] Xia Jian, Qian Peidong, Zhu Wei. Study on causes of early blue-green algae bloom in Lake Taihu in 2007. Scientia Meteorologica Sinica, 2009, 29(4): 531-535(in Chinese with English abstract). [夏健, 钱培东, 朱玮. 2007 年太湖蓝藻水 华提前暴发气象成因探讨. 气象科学, 2009, 29(4): 531-535.]

[16] Wu Xiaodong, Kong Fanxiang. The determination of in situ growth rates of the bloomed Microcystis in Meiliang Bay, Lake Taihu. China Environmental Science, 2008, 28(6) : 552-555( in Chinese with English abstract). [吴晓东, 孔繁翔. 水华 期间太湖梅梁湾微囊藻原位生长速率的测定. 中国环境科学, 2008, 28(6) : 552-555.]

[17] Tao Yi, Kong Fanxiang, Cao Huansheng et al. Simulative recruitment of Microcystis from the surface sediment in Lake Taihu. J Lake Sci, 2005, 17(3) : 231-236(in Chinese with English abstract). DOI : 10.18307/2012.0312. [陶益, 孔繁 翔，曹焕生等. 太湖底泥水华蓝藻复苏的模拟. 湖泊科学, 2005, 17(3) : 231-236. ]

[18] Tan Xiao, Kong Fanxiang, Yu Yang et al. Effects of enhanced temperature on algae recruitment and phytoplankton community succession. China Environmental Science, 2009, 29(6): 578-582(in Chinese with English abstract). [谭啸, 孔繁 翔, 于洋等. 升温过程对藻类复苏和群落演替的影响. 中国环境科学, 2009, 29(6) : 578-582.]

[19] Zhang M, Yang Y, Zhen Y et al. Photochemical responses of phytoplankton to rapid increasing-temperature processpre. Phycological Research, 2012, 60(3) : 199-207.

[20] Cao HS, Tao Y, Kong FX et al. Relationship between temperature and cyanobacterial recruitment from sediments in laboratory and field studies. Journal of Freshwater Ecology, 2008, 23(3) : 405-412.

[21] Huang Wei, Zhao Laijun. Identification model of mignificant impact factors for cyanobacterial bloom. Journal of University of Shanghai for Science and Technology, 2012, 34(5): 435-440( in Chinese with English abstract).[黄炜, 赵来军. 蓝 藻水华显著影响因子识别模型. 上海理工大学学报, 2012, 34(5): 435-440.

[22] Chen YW, Gao XY. Study on variations in spatial and temporal distribution of Microcystis in Northwest Lake Taihu and its relations with light and temperature. In: CAI Qiming ed. Ecology of Lake Taihu. Beijing: China Meteorological Press, 1998: 142-148.

[23] Hua JB, Zong ZX. Experimental research on formation of algae bloom in Yanghe reservoir. Acta Scientiarum Naturalium Universitatis Pekinensis, 1994, 30(4) : 476-484.

[24] Duan Hongtao, Zhang Shouxuan, Zhang Yuanzhi. Cyanobacteria bloom monitoring with remote sensing in Lake Taihu. J Lake Sci, 2008, 20(2) : 145-152 (in Chinese with English abstract). DOI : 10.18307/2008.0202. [段洪涛, 张寿选, 张 渊智. 太湖蓝藻水华遥感监测方法. 湖泊科学, 2008, 20(2) : 145-152.]

[25] Han Xiuzhen, Wu Chaoyang, Zheng Wei et al. Satellite remote sensing of cyanophyte using observed spectral measurements over the Lake Taihu. Journal of Applied Meteorological Sciences, 2010, 21(6): 724-731(in Chinese with English abstract). [ 韩秀珍, 吴朝阳, 郑伟等. 基于水面实测光谱的太湖蓝藻卫星遥感研究. 应用气象学报, 2010, 21(6): 724-731.]

[26] Hu CM, Lee ZP, Ma RH et al. Moderate Resolution Imaging Spectroradiometer (MODIS) observations of cyanobacteria blooms in Lake Taihu, China. Journal of Geophysical Research, 2010, 115(C04002) : 1-20.

[27] Shang Zhaotang, Ren Jian, Qin Mingrong et al. Relationships between climatic change and cyanobacterial bloom in Lake Taihu. Chinese Journal of Ecology, 2010, 29(1) : 55-61 (in Chinese with English abstract). [ 商兆堂, 任健, 秦铭荣. 气 候变化与太湖蓝藻暴发的关系. 生态学杂志, 2010, 29(1) : 55-61.

[28] Wang Chenglin, Pan Weiyu, Han Yueqi et al. Effect of global climate change on cyanobacteria bloom in Lake Taihu. China Environmental Science, 2010, 30(6) : 822-828(in Chinese with English abstract). [王成林, 潘维玉, 韩月琪等. 全 
球气候变化对太湖蓝藻水华发展演变的影响. 中国环境科学, 2010, 30(6): 822-828.]

[29] Wang Mingwei, Xu Qixin, Che Yue et al. Research on the meteorological and hydrological factors of cyanobacteria bloom in Lake Dianshan. Journal of East China Normal University: Natural Science, 2011, (1):21-31(in Chinese with English abstract). [王铭玮, 徐启新, 车越等. 淀山湖蓝藻水华暴发的气象水文因素探讨. 华东师范大学学报: 自然科学 版, 2011, (1): 21-31.]

[30] Cheng Xiaoying, Li Shijie. An analysis on the evolvement processes of lake eutrophication and their characteristics of the typical lakes in the middle and lower reaches of Yangtze River. Chinese Science Bulletin, 2006, (7) : 848-855(in Chinese with English abstract). [ 成小英, 李世杰. 长江中下游典型湖泊富营养化演变过程及其特征分析. 科学通报, 2006, (7) : 848-855.

[31] Yu Jianqiao, Lü Xueyan. Analysis on the occurring conditions for RS detective blue-green algae bloom in Lake Taihu. Environmental Science \& Technology, 2015, 38(6): 93-98(in Chinese with English abstract). [ 郁建桥, 吕学研, 太湖遥 感可测性蓝藻水华发生条件分析. 环境科学与技术, 2015, 38(6) : 93-98.

[32] Reynolds CS. Cyanobacteria water blooms. In: Callow JA ed. Advances in botanical research. London: Academic Press, 1987: 67-143.

[33] Kong Fanxiang, Song Lirong eds. Study on the formation process and environmental characteristics of cyanobacteria bloom. Beijing: Science Press, 2011 (in Chinese).[ 孔繁翔, 宋立荣. 蓝藻水华形成过程及其环境特征研究. 北京: 科学出 版社, 2011.]

[34] Thomas RH, Walsby AE. Buoynacy regulation in a strain of Microcystis. Journal of General Microbiology, 1985, 131: 799809.

[35] Reynolds CS, Rogers DA. Seasonal-variations in vertical distribution and buoyancy of Microcystis aeruginosa Kutz Emend Elenkin in Rostherne-mere, England. Hydrobiologia, 1976, 48(1) : 17-23.

[36] Robarts RS, Zohary T. Temperature effects on photosynthetic capacity, respiration and growth rates of bloomforming cyanobacteria. New Zealand Journal of Marine and Freshwater Research, 1987, 21(3) : 391-399.

[37] Wu Xiaodong, Kong Fanxiang, Zhang Xiaofeng et al. Comparison of overwintering and recruitment of cyanobacteria in Lake Taihu and Chaohu Lake. Environmental Science, 2008, 29(5): 1313-1318(in Chinese with English abstract). [ 吴晓东, 孔繁翔, 张晓峰等. 太湖与巢湖水华蓝藻越冬和春季复苏的比较研究. 环境科学, 2008, 29(5): 1313-1318.]

[38 ] Liu Yusheng, Han Mei, Liang Zhanbin et al. Influence of light intensity, temperature and nutrients on the growth of Microcystis in water of Lake Dianchi. Research of Environmental Sciences, 1995, 8(6) : 7-11 (in Chinese with English abstract). [刘玉生, 韩梅, 梁占涁等. 光照、温度和营养盐对滇池微囊藻生长的影响. 环境科学研究, 1995, 8(6) : 7-11.]

[39] Miao Can. Analysis of phytoplankton chlorophyll-a in summer and autumn in Lake Chaohu and the impact factors of Cyanobacteria blooms [Dissertation]. Hefei : Anhui University, 2008(in Chinese with English abstract). [缪灿. 巢湖夏、秋季 浮游植物叶绿素 a 及蓝藻水华影响因素分析 [学位论文]. 合肥: 安徽大学, 2008.

[40] Jin Jianping, Yu Xin, Bao Yunxuan et al. Study on the relationship between the cyanobacteria density and the previous environmental factors in the east part of the Lake Yangcheng. Chinese Journal of Agrometeorology, 2013, 34(3) : 324-331 (in Chinese with English abstract). [ 金建平, 于釒金, 包云轩等. 阳澄湖东湖蓝藻密度与前期环境因子的关系. 中国农 业气象, 2013, 34(3) : 324-331.] 